\title{
Modeling contractor and company employee behavior in high hazard operation
}

\author{
Pei-Hui Lin, Daniela Hanea, Ben J.M. Ale \\ Safety Science, Technical University Delft, Delft, The Netherlands
}

\begin{abstract}
The recent blow-out and subsequent environmental disaster in the Gulf of Mexico have highlighted a number of serious problems in scientific thinking about safety. Risk models have generally concentrated on technical failures, which are easier to model and for which there are more concrete data. However, many primary cause of the disasters, such as BP's Texas City and Deepwater Horizon, are rooted in management decisions and organizational. Therefore, there is a strong need to develop a risk management support tool for chemical process industries which incorporates human and organizational factors into quantified risk models. In this paper, we model two human performance model for oil and gas company Royal Dutch Shell. Interviews were conducted to obtain important human factors. As the quality and operation of the management actions have important influences on human factors (e.g. safety attitude, training), we have linked a safety management model with the human factors model and quantify the risk implications of different management changes to prevent accidents. The methodology of integrating organisational factors into a Bayesian Belief Networks (BBNs) model is discussed in Lin et al. (2012). In this paper the development and quantification of human and management factors for an international oil company is given.
\end{abstract}

\section{INTRODUCTION}

It is now widely acknowledged that human failure and organizational factors are the fundamental causes of many major accidents and incidents, e.g. Texas City, Piper Alpha, Chernobyl. However, introducing human factors and organizational factors into risk models is a big challenge in the current worldwide research, mainly due to poor data availability and the difficulty of capturing soft variables in an appropriate and quantifiable way (Lin, 2011). To make the human factors amenable for quantification, the human factors have to be translated into proxy quantities. How to model the human factors and the management factors by the proxy variables without losing their actual influences is one of the main challenges in risk modelling for human factors.

The objective of this paper is to incorporate human factors into the risk assessment model of oil and gas operations within the technical risk model for Royal Dutch Shell. In this paper we illustrate the quantification steps and the questions designed for reducing the current quantification limitations for human factors in oil industry.

Section 2 provides a brief overview of the quantification method for human factors. Human models for two types of people: the companies own personnel and the personnel hired through contractors are built. The structure of the human models and their development are described in more detail in section 3. The influences of management on human model are shown in section 4 . This section also discusses the influence of management which follows with the conclusions.

\section{LINKING HUMAN FACTORS IN SAFETY BARRIERS IN THE CAUSAL PATHWAY}

Figure 1 shows a BBN for a vessel or vessel-like equipment. All the barriers indicated have the purpose of preventing a loss of containment. Barrier failures occur when at least one out of three generic barrier functions are broken. These functions are

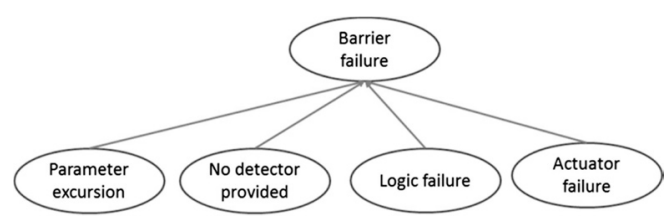

Figure 1. One layer protection system. 
described by the validity rules for a barrier in Layer Of Protection Analyses (LOPA) and Hazards and Effects Management Process (HEMP). For a barrier to be valid, it has to have a detection function; when this fails an alarm is not available. It has to have a logic function; when this fails the alarm does not propagate into a response. Finally it has to have an actuator function; when this fails the response to the alarm does not contain or reduce the risk of an LoC. The barrier failures are sometimes human performance nodes. This can be direct action by human, where an operator serves as the logic processor and actuator of a barrier (e.g. when someone fails to observe an alarm or react to it). It could also be by indirect action such as wrong specification of alarm or other design errors. In the generic BBN whenever a node depends on a human to perform a task, a human performance model is attached to that specific node.

More detail description can be seen in Ale et al., this conference.

\section{HUMAN MODEL}

\subsection{Human model}

In order to account for the influence of human factors on accident causation, the human factors are best represented in the BBNs because it involves probabilistic influences of human factors rather than deterministic cause-effect relations. Extra care was taken for identifying and modeling those human factors when defining the nodes (section 3.2) and designing the questions (section 3.3.2).

A set of human factors has been selected after a review of literature (Gordon et al., 1996; Gordon 1998; HSE UK) and discussion between the experts in Royal Dutch Shell. The first step to quantify the human factors in the BBNs is to describe the variables in precise terms.

\subsection{Quantification of the human model}

To describe the different variables in precise terms, we have to consider the fact that continuous BBNs require all variables to have values that can be ordered.

Not only that each of the nodes has to be defined in a precise way, but also they have to have values which can be ordered. Besides, when they are operationalized they have to reflect potential and actual influences related to qualitative analysis seen by the field experts. So, first step is to reach consensus regarding what is the definition of each node. For example, what is competence defined? Does everybody mean the same by competence?
Then, how can we quantity this? Can we find numerical values or have to be defined as, for example, low/medium/high? And then, what does each of these three levels mean? This step of model quantification is very time consuming and has to be done through a series of meeting with people working in the company.

In the generic paper (Ale et al., this conference), the barrier failures are sometimes human performance nodes. This can be direct action by human, where an operator serves as the logic processor and actuator of a barrier (e.g. when someone fails to observe an alarm or react to it). It could also be by indirect action such as wrong specification of alarm or other design errors. In the generic BBN whenever a node depends on a human to perform a task, a human performance model is attached to that specific node. The top event in the human performance model refers to the tasks done by the company personnel or by the contractor. As explained in the current project (Ale et al., this conference), we concentrate on finding the probability distribution of the frequency of Loss Of Containment (LOC). Hence, we confine the human tasks in this research to HSSE critical tasks. Hence, the human failure defined in this research is "the likelihood that a task is performed with one or more errors which are not immediately recovered and in the end have the potential to lead to an incident/accident in process safety (LOC)".

In the current implementation of the method we distinguish two types of people: the companies own personnel and the personnel hired through contractors. This distinction has been made because personnel hired by contractors are under the managerial influence not only of the company under study but also of the contractor company by which they are employed.

Table 1 shows the definition of human failures and the final list of the selected human factors for the contractors for this company under study. The human factors for the company employee are similar, but the data going into it is not.

Figure 2 shows the (inter)relations between the model variables in BBN structure. Each variables identified in Table 1 is presented as a node in the model. The heading of "commitment" driving the behavior of the people involved in safety is further broken down (Sillem et al., 2013).

\footnotetext{
${ }^{1}$ When we speak about HSSE (Health Safety Security Environment) critical tasks performed by company personnel, we talk about tasks such as: react on the high pressure alarm, temporarily override and reinstall safety features (barriers), authorise people to do so, execute start-up and shutdown procedures, etc.
} 
Table 1. Human factors (contractors).

\begin{tabular}{|c|c|}
\hline Variable & Definition \\
\hline Contractor performance & $\begin{array}{l}\text { The likelihood that a task is performed with one or more errors which in } \\
\text { the end hamper the operation }\end{array}$ \\
\hline $\begin{array}{l}\text { Procedure (including checklist, } \\
\text { work instruction or other job aids) }\end{array}$ & $\begin{array}{l}\text { The likelihood that work instruction that is not available, accurate, safe, } \\
\text { clear, up-to date and easy to read and understand }\end{array}$ \\
\hline Competence & $\begin{array}{l}\text { The likelihood that the operators do not have sufficient knowledge/skill/ } \\
\text { experience to execute a particular task }\end{array}$ \\
\hline Capacity to work & $\begin{array}{l}\text { The likelihood that the operator shows the sign of in-availability (including } \\
\text { fitness to work, alertness, physical state, and psychological state) }\end{array}$ \\
\hline Job specific communication & $\begin{array}{l}\text { The likelihood that during permit to work/shift/on the job communication, } \\
\text { the required information (job hazard, safety precaution) is not trans- } \\
\text { ferred to the operators }\end{array}$ \\
\hline Human factors in design & $\begin{array}{l}\text { The likelihood that equipment and work stations are not designed for easy } \\
\text { access and easy operation and maintenance }\end{array}$ \\
\hline Contractor performance & $\begin{array}{l}\text { The likelihood that during critical activities the individual does not carry } \\
\text { out the required behaviour at the right moment, with the right care and } \\
\text { attention to detail in order to control the risk }\end{array}$ \\
\hline
\end{tabular}

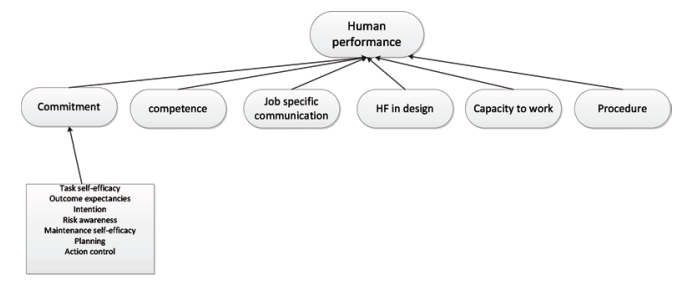

Figure 2. Human performance model (contractors).

\subsection{Data gathering through expert elicitation}

Since no data were available in the current study, structured expert judgment method is used in this study (Cooke, 1991; Cooke \& Goossens, 2000). All marginal distributions for each node and rank correlations between nodes were retrieved by structured expert judgment following the elicitation procedures described in Morales et al. (2010). The quantification process is briefly recapitulated here.

- Assess a marginal distribution for each node

- Assess a conditional rank correlation for each arc

See Lin et al. (2012) for more detailed quantification explanation.

We gather these information by extensive inquiries among experts at one of the sites of the company under investigation.

Fourteen experts were selected for the expert elicitation exercise. They were selected based on the expectation that they have dealt with safety matters, have a broad view of human factors and/or deal with (safety)management of humans on-site.

Both the contractor human model and the company personnel model were elicited this way.

\subsubsection{Elicitation procedure}

Prior to the elicitation sessions, a standardized set of questions was designed. These questions are focused on the critical tasks done by the contractors/company personnel in one of the sites of the company under study.

During the elicitation session, which was held with two researchers and a single interviewee, the purpose and procedure of the elicitation was explained to the interviewee. This allows the experts to pose questions about definition and quantification method. Then the questions are given to the interviewee so that he or she can read and answer them. The researchers remain present so that they may answer questions.

\subsubsection{Questionnaire design}

The questionnaires that followed from the design consists of three parts:

- The first part is focused at acquiring a marginal distribution

- The second part is focused at acquiring the rank correlation (the arcs between the nodes)

- The last part is capturing the expert uncertainty.

- In the first part of the questionnaire, experts are asked to assign their estimates and their uncertainties in a structured way.

Consider the question regarding to competence.

"Consider 1,000 critical tasks chosen at random from company site. How many of these tasks will the contractors do not have sufficient knowledge/skill/ experience about the hazard and working practice?"

To capture the uncertainty, the expert has to assign the 50th quantile (the median values of the 
distribution), the $5 \%$ quantile value (which would surprise you if more than 50 out of 1000 samples have a value lower than this value), and the $95 \%$ quantile value (which would surprise you if more than 50 out of 1000 samples have a value higher than this value).

The weights for the linear combination are computed based on experts' answers for a set of variables (called seed variables) whose values are known to the analyst but unknown (at least at the moment of the interview) to the experts. The combination of experts' answers is used further as the distribution of the variable in the model.

- The second part of the questionnaire aims for the elicitation of the rank correlations. This procedure involves four steps:

- Step 1: Ask the experts to assign the relative importance between the human factors (e.g. which is more important? procedure, competence, communication, fatigue...);

- Step 2: Ask the experts the directions (positive/negative) of influences to contactor human failure. For instance: do high levels of fatigue relate to high or low values of contractor human failure?;

- Step 3: For the variable that expert ranked highest (e.g. competence), we ask the expert to estimate the conditional probability between human error and competence (a measure for the size of the influence). This estimate is the conditional probability $\mathrm{P}(\mathrm{X}>$ median $\mathrm{X} \mid \mathrm{Y}>$ median $_{\mathrm{Y}}$ ). In this case $\mathrm{X}=$ human error and $\mathrm{Y}=$ competence;

- Step 4: For the remaining variables, we ask the experts to indicate their influence proportional to the influence of the variable that they regarded highest (in percent).

Once the expert has given an estimate for the execeedance probability for the highest variable and the fractions of influences of this variables comparing with the others on their child node, the rank correlations for all the arcs can be computed.

- To capture expert uncertainty, the expert was asked to assign his/her uncertainty regarding the third set of questions: the seed questions. These questions are questions for which the investigators know the answers. Calibration questions were derived from Oil and Gas Production report (OGP), company people survey, and company sustainability report. It should be noted that the scope of using seed questions is not to assess how good the expert is in the field, but how good the expert in quantifying the uncertainty on variables. So these questions are used to measure and validate the expert performance in uncertainty quantification.

Next section shows the influences of management on human model. The robustness analysis of the expert judgment is presented in another paper in this conference (Hanea, 2013a). Another paper (Hanea, 2013b) shows the quantification results for company employees and contractors and discusses the differences between them.

\section{MANAGEMENT INFLUENCES ON CONTRACTOR HUMAN PERFORMANCE MODELS}

The influence of management is modeled through connections to the human performance model as was done before in the CATS (2009) project.

\subsection{Management influences}

A number of management interventions are possible to improve human factors, e.g. competence. When some form of improvement occurs, the 'better' part of the distribution in the node is used in the BBN conditionalising calculation, thereby representing an improvement of the competence. However, not all interventions are equally efficient. Say, education is more efficient than a procedure upgrade. Then the management factors quantify just how much the competence improves. This information is fed to the bottom of the BBN: in the human factors. Figure 3 demonstrates where the management models influence the BBN. This influence propagates through the $\mathrm{BBNs}$ model and eventually has an impact on the probability of LOC.

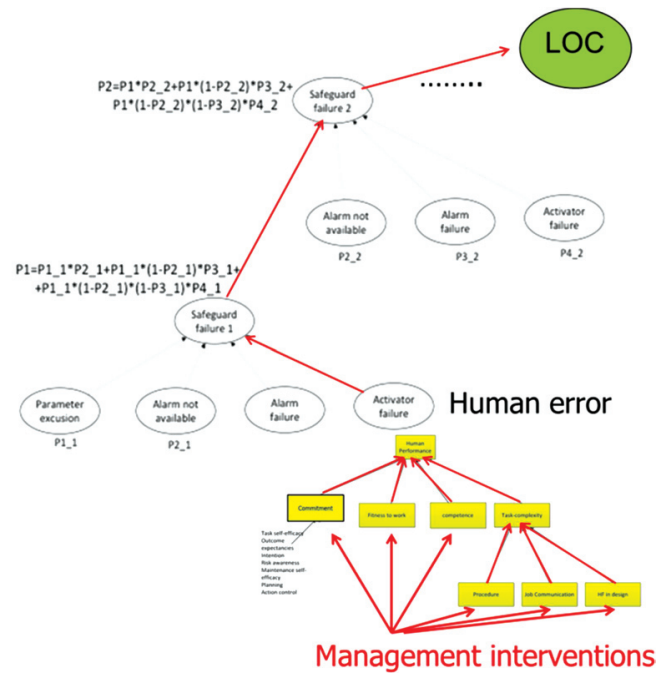

Figure 3. Management influences on the chain of barriers. 
Table 2. Preliminary list of management interventions for reducing contractor communication errors identified by interviewees.

Less and better safety moments which are more related to the task of the workers

Buddy system (focal point for a specific contractor)

Clear task risk analysis in work preparation and before people go into the task

Personally speak with contractors/management contractor

Safety stands still, toolbox talks

Safety observation rounds/go \& see
Have a HSE kick off meeting before starting a big/ complicated maintenance task

Company HSE person available in the filed continuously

Company-contractor meetings at working level

Repeat message in different form

Allow time for communication

Permit to work (in electronic form)

\subsection{Quantitative input: Data structure and data gathering}

The management modelling builds upon earlier work in the CATS project. (Bellamy et al., 1999; Hourtolou \& Salvi, 2003; Hale \& Guldenmund, 2004; RIVM, 2008; Ale et al., 2007). The starting point for modelling is that management has to perform a number of tasks to maintain safety barriers. They are defined as follows:

- provide barriers: specify, design and procure technology or human tasks and procedures that function as safety barriers;

- use barriers: see to it that barriers function, technologies are operating and or critical human actions are carried out;

- maintain barriers: ensure that barriers remain operating to the designed level; and

- monitor barriers; check functioning of technology or people through audits or observations over prolonged lengths of time to ensure that the original design remains valid and that no degradation takes place.

For these tasks eight deliveries or "components of working safely" were distinguished in I-Risk (Bellamy et al., 1999) and CATS (Ale et al., 2009): (1) Procedures; (2) Equipment; (3) Man-machine interface; (4) Availability; (5) Communication; (6) Competence and (7) Commitment. They are called deliveries because they are risk controls, instructions and resources that management should deliver to the tasks. Possible management interventions relevant to a particular human factor can be generated under the heading of the delivery systems.

The challenge is to acquire a complete overview of the possible management interventions. Several sources can be used to gather this kind of information: discussion with experts, interviews, observation, work-document analysis and literature. A preliminary list of potential management interventions was derived from the interviewees for the expert elicitation of the
Table 3. Group opinion on communication $(n=5)$.

\begin{tabular}{lll}
\hline Item \# & Management action & Weighting \% \\
\hline 1 & $\begin{array}{l}\text { Company-contractor meetings } \\
\text { at working level } \\
\text { Buddy system (company } \\
\text { focal point for a specific } \\
\text { contractor) }\end{array}$ & $32 \%$ \\
Have a HSE kick off \\
meeting before starting \\
a big/complicated \\
maintenance task \\
Less and better safety moments \\
which more related to \\
the task of the workers
\end{tabular}

human performance model. Table 2 shows this list ${ }^{2}$.

Determining the relative weight of each factor is based on the paired comparison method (Lin et al., 2012, Lin et al., 2013). An example, for illustration only, is given in Table 3 of the results for the 5 management interventions.

Table 3 gives an example of which factors would have the greatest influence on safety performance in the fictional example presented here. Lin (2013) has designed a methodology to link the management decisions with the BBN. Suppose the company managers decide to implement the first 3 management actions in table 3 , then changing the parameters for communication in the BBN would lead to a reduction of $2,7 \%$ in the probability of LOC. This fictitious example demonstrates the influences of three management actions that could be implemented by the company under study.

\footnotetext{
${ }^{2}$ This is an examples, not a complete list.
} 


\section{CONCLUSIONS}

In this paper, we show a human performance model for Royal Dutch Shell. Extra care was taken to identify and model human factors when designing the expert elicitation questions. This makes the quantified model better represent potential and actual influences relative to qualitative analysis seen by the field experts. As the quality and operation of the management actions have important influences on human factors, we have linked a safety management model with the human factors model and quantified the risk implications of different management changes aimed at preventing accidents in the oil industry. This model could become an extra tool to help decision makers in oil industry determine which management interventions have the greatest potential to reduce risk in the operation.

\section{ACKNOWLEDGEMENT}

This work reported above was fully funded by Royal Dutch Shell plc.

\section{REFERENCES}

Ale, B.J.M., Bellamy, L.J., Cooke, R.M., Goossens, L.H.J., Hale, A.R., Roelen, A.L.C. and Smith, E. (2006). "Towards a causal model for air transport safety - an ongoing research project." SAFETY SCIENCE 44(8): 657-673.

Ale, B.J.M., Baksteen, H., Bellamy, L.J., Bloemhof, A., Goossens, L.H.J., Hale, A.R., Mud, M., Oh, J.I.H., Papazoglou, I.A., Post, J. and Whiston, J.Y. (2007). "Quantifying occupational risk: The development of an occupational risk model." Safety science 46: 176-185.

Ale, B., Bellamy, L.J., Cooke, R.M., Duyvis, M., Kurowicka, D., Lin, P.H., Morales, O., Roelen, A.L.C., Spouge, J.. 2009. Causal Model for Air Transport Safety - Final report. Ministerie van Verkeer en Waterstraat, Directoraat-Generaal Luchtvaart en Maritieme zaken. ISBN 13: 97890369 1724-7,

Ale, B.J.M, Ababei D., Gulijk, C. van, Hanea D., Hudson P., Lin, P.H., Sillem, S., Steenhoek, M., Further development of a method to calculate frequencies of Loss of Control including their uncertainty. ESREL 2013 (This conference).

Bellamy, L.J., Papazoglou, I.A., Hale, A.R., Aneziris, O.N., Ale, B.J.M., Morris, M.I. and Oh, J.I.H. (1999). Developmenet of an integrated technical and managmeent risk control and moniitoring methdology for managing and quntifying on-site and off-site risks, I-Risk main report. EU Contruct number ENVA CT96-0243, Ministry of Social Affairs and Employment, Den Haag. Den Haag Ministry of Social Affairs and Employment.
Cooke, R.M. (1991). Experts in Uncertainty: opinion and subjective probability in science, New York: Oxford University Press.

Cooke, R.M. and Goossens, L.H.J. (2000). Procedures guide for structured expert judgment. Technical Report EUR 18820. Brussels, Belgium, European Commission.

Gordon, R.P.E. (1996), R.H. Flin, K. Mearns, M.T. Fleming. Assessing the Human Factors Causes of Accidents in the Offshore Oil Industry, SPE Health, Safety and Environment in Oil and Gas Exploration and Production Conference, 9-12 June 1996, New Orleans, Louisiana.

Gordon, R.P.E. (1998). The contribution of human factors to accidents in the offshore oil industry, Reliability Engineering \& System Safety 61 (1-2): 95-108.

Hale, A.R. and Guldenmund, F. (2004). ARAMIS audit manual, version 1.3. Safety Science Group, Delft University of Technology, Delft, the Netherlands, Safety Science Group, Delft University of Technology, Delft, the Netherlands.

Hanea, D, P-H, Ale, B.J.M. 2013a. Robustness analysis of structured expert judgment on human factors. ESREL 2013 (This conference).

Hanea, D, P-H, Ale, B.J.M. 2013b. Quantification of human factors in hazardous industry using structured expert judgment (This conference).

Hourtolou, D. and Salvi, O. (2003). ARAMIS project: development of an integrated accidental risk assessment methodology for industries in the framework of SEVESO II directive. Safety and Reliability-ESREL T., B. and P.H.A.J.M., V.G.: 575-581.

HSE, UK http://www.hse.gov.uk/humanfactors/index. $\mathrm{htm}$.

Lin, P.H., Safety Management and Risk Modelling in Aviation, Delft, The Netherlands, 2011. ISBN: 9789079787326 (doctoral thesis).

Lin, P.H., Hale, A.R., Gulijk, C. van. A paired comparison approach to improve the quantification of management influences in air transportation, Journal of Reliability Engineering \& System Safety 113(1), 2013.

Lin, P.H., Hanea, D., Ale, B.J.M., Sillem, S., Gulijk, C van, Hudson, P. 2012. Integrating organisational factors into a BBN model of risk. PSAM 11, Esrel 2012, Helsinki 25-29 juni 2012.

Morales Nápoles, O. (2010). Bayesian belief nets and vines in aviation safety and other applications. $\mathrm{PhD}$. thesis, Delft University of Technology.

RIVM (2008). The quantification of occupational risk: The development of a risk assessment model and software. Report 620801001/2008. National Institute for Public Health and the Environment.

Sillem, S., Lin, P-H, Ale, B.J.M. 2013. Modelling human motivation in a high-risk operation. ESREL 2013 (This conference). 